\title{
Civilisation modes and ecology constraints
}

\begin{abstract}
The «civic modes are men's invention; they distinguish the human societies, due to lawful behaviours and urbane habits. After birth, the human babies receive education and teaching, aiming at culture and ethics issues. The children develop abstraction talent, creating 〈knowledge〉, 〈relational〉 help for 〈idiom〉, 〈trade〉 and 〈authority〉. These are 〈interpersonal〉 practices, built by 〈intellect〉 by 〈meme fruition〉: they devise 〈progress〉, via agrarian and industry, to cognition ages and via civic modes, renewed by social breakthroughs. The 〈relational〉 routines enjoy implicit force by 〈inner〉 or 〈upper〉 motives, resorting to a priori cosmos' information or divine steering/will; the man's civilisation is so impressive fact that the unspoken reasons are current belief. Today, the extant lawful deeds and urbane lifestyles, told «civic modes〉 of «sovereign countries〉, become object to 〈ecology> kerbs. When dealing with the material world, the 〈relational〉 models are contingent depictions; the <ecology〉 constraints, however, show the lack of coherence of given 〈civic modes〉, starting from the «split-sovereignty〉 of the 〈nation-states〉 and suited deepening is useful.
\end{abstract}

\author{
Volume 3 Issue 6 - 2018
}

\author{
Rinaldo C Michelini Di San Martino \\ University of Genoa, Italy
}

Correspondence: Rinaldo C Michelini Di San Martino, University of Genoa, Italy, Email michelini@dimec.unige.it

Received: December 18, 2018 | Published: December 19, 2018

\section{Introduction}

The human 〈progress〉 is achievement built on earth, using 〈intellect〉 procedures, altering the natural setups by men's conceived and implemented actions. The developments make resort to «knowledge〉, say, culture and ethics artefacts, carrying civic and social falloffs. The 〈intellect〉 or «mind» shapes through interpersonal activity, which create multilevel 〈societies〉. The 〈relational〉 description distinguishes communication (language), trade (market) and authority (government) functions, to connect the «minds〉 of educated individuals within the established 〈societies〉. The verbal talent is complex feat, but it implies a teacher and needs training, once mimicry is retained practice. The simulation and emulation performances tell that men play the roles of actors/tutors and of spectators/pupils. The understanding requires coachers, supplying backdrops and reading keys. The 〈relational〉 path entails players/watchers, educated by instructors. The abstract domains ( kknowledge〉, etc.) develop via linked methods and tools («communication), etc. and 〈idiom», etc.). The tutoring and training concern the outfits in view of the awarded functions.

The 〈relational〉 formation is aftermath of interacting 〈minds»: the mental copies have encoded versions, common to the clan; the readings address shared canons. The idiom's meanings identify voices, by sets of sounds (verbal entry) and symbols sets of letters (graphic entry), selected by the clan and tribe. The issue is meaningful, if a relevant community shares the devised data encoding, as mental wherewithal. The course specifies semantic traits of «knowledge〉; these are 〈language〉 instances, when fused to convey thoughts, keeping appraisals and doubts. The communication-to-knowledge track is construct assignment. The 〈relational〉 design avails of other intellect courses: the market-to-finance and the headship-togovernance are main social organisation results, built on citizens' interpersonal skills, to back, besides communication, also business and authority. The 〈relational〉 structures perform duties, consistent with the brains of the interfaced individuals, by means of the learned rules, ratified as acknowledged ethics or lawfulness.

The outlined picture links 〈progress〉, 〈intellect〉 and 〈knowledge〉, abstract notions, which are earth oddness, once we look at the universe around us. The earth, actually, is negligible planet, which, however, characterises by peculiar processes, just enjoying local evidence:
1. The 〈biology〉, producing life forms and life cycles, up to individual life beings;

2. The «cognition», fashioning culture and ethics artefacts, as explanatory clues.

3. In the picture, 〈biology〉 and 〈cognition〉 are singularities, a posteriori explained, when collecting the useful 〈lifeform» and «knowledge». The discussions of the topics follow the scheme:

4. The analyses of earth's anomalies, from 〈knowledge to 〈civic features; ;

5. The narration of the 〈authority〉 frames and of the 〈governance〉 settings;

6. The depiction of running options, managing autonomy and competition;

7. The «ecology shocks and the global controls of effluence, for recovery.

The «cognition s is the anomaly through which the men, inhabitants of a negligible planet, build models, describing the cosmos' features, by the developed 〈knowledgè. The mind outputs are the intangible «culture», science, technology taken in, or 〈ethics», social and legal modes included. The created 〈human civilisation〉 needs several intellect by-products: the «civic traits might follow the a posteriori 〈relational〉 path; the achievements, however, are so complex that an a priori path is possible alternative, if one has faith in the existence of 〈cosmos' information〉 aimed at the human 〈progress〉. The «civic features) of the two paths seam showing peculiarities on the governance up to 〈sovereignty), conflicting against the «ecology) drawbacks, lately, discovered. The discussion is developing on these themes, helps assessing the 〈relational〉 model, when reviewing the 〈human civilisation〉 deployments.

\section{The cognition process}

〈Biology〉 and 〈cognition〉 are earth's peculiarities, maybe, cosmos' information, which has trial detection as «natural laws〉. The 〈biology〉 enjoys apt reading by the Darwin's models and the gene evolution. The genome decoding supplies data, telling the life adaptation, to the surrounds. The 〈cognition〉 does not possess guess on why men's 
brains turn in minds (and not the ones, e.g., of orangutan's), through child's parental teaching. The hardware/software/firmware variations open queries, being hard distinguishing new items or new ideas, when the intellect invents or accepts instant guesses. The sketched ways of 〈biology〉 and 〈cognition〉 have complementary outcomes:

1. The creation of individuals, up to men, moving from the living beings of many species;

2. The establishment of awareness, up to culture/ethics codes, from knowledge design.

The 〈biology〉 concerns the depiction of agentive matter: the lifeforms. The gene evolution says that the life beings modify, adjusting to outer stimuli. The fashioned individuals, at the end, are active and intelligent: the (intellect) develops through the relational ability. The men accomplish tasks and decide their plans with responsible awareness. The framework implies suited picks, to enable factual creation of interactive minds, endowed of learning and decision talents, since:

1. The intelligence skill allows to choose among (inter-legere), using personal freedom;

2. The rationality knack supports interpersonal conception, by mental cross processing.

The intellect deployments involve tribes or nations, which start assembling, under common government within «closed societies〉. The interpersonal understanding and the free choice are planning aids, which supply benefits, when the selected culture/ethics techniques deliver proper provisions. The intelligence, by relational innovations, permits the civilisation build-up, by means of a set of changes in the civic behaviours of the organised communities, through:

1. technology revolutions, devising productivity techniques, with value-added boosts;

2. social breakthroughs, implementing civic organisations, to increased effectiveness.

The latter establish in 〈closed societies〉, justifying local reigns, with allotted self-ruling. The creation of the «nation〉 is tangled prospect, fulfilled enabling typical functions, namely:

1. the administration: clerical tasks, for the inward prepared steering of the citizens;

2. the governance: control operations for the cross and inside nation's management;

3. the supremacy: hierarchic directives, under headship or representative authorities.

The functions use relational spheres, performing bureaucracy, organisation and leadership acts, with the country officialdom. The communication and the clerical roles have known mimicry spell; the authority ranks get meme fruition assessments, which show the actual usefulness of the setup; the hierarchic directives do not apply, until when emulation/simulation aids supply on-duty proofs of the obtained efficiency. The 〈cognition〉 process, hence, has sly layout, which is obvious, only, along the communication-to-knowledge track; it turns plain, dealing with the market-to-finance path and tricky, when looking at the headship-to-governance one, markedly, if the social layouts switch, from a posteriori factual business, to a priori nominal authority.
The 〈cognition〉 process has starts by the 〈language invention, which characterises men, out of the other living beings: it is the way, by which scholars build the knowledge. The verbal creation is collective activity at semantic choice and at thought build-up: the symbolism exploits trace links; the sentence construal follows grammar and syntax rules, which define at interactive range. The 〈knowledge〉 synthesis is choice of learned scholars, prospecting construal blends, implementing theories or providing innovations to the extant arts and crafts establishments. The «knowledge is current success, available to the given clan; the mental resources are on duty contributory ways: the instrumental utility is clear; the definite bustle has implicit proof, if we think that our science and our understanding are reliable backing, to programme our future. Presently, nevertheless, no proof is available: only factual checks are delayed, when we see that progress or regress follows.

The empirical assessment on the building of «social structures〉 by 〈relational〉 means repeats at different levels: friendly understanding, bilateral engagement and top-down obligation. Each time, the involved 〈knowledge operates in specialised 〈civic〉 contexts〉, meaning by that the creation of interpersonal links, to establish sociability, business or control. The «civic modes s are, then, worthy implementations due to communication by the idiom's invention, to trade by market's ideation or to government by authority's discovery. The created relational links are strange issues: they bond by the parlance mutual comprehension of the clan, by the economic cross coupling of the partners or by the sovereignty compliance of the assembly. Languages, markets or regimes supply example applications and engagements, so that the effected «civic modes〉 are possible instances, object of changes and improvements, since the innovation entails the performed functions.

\section{Organisation of collective layouts}

From the «knowledge», we derive the «civic features to organise effective collective setups. To start, the 〈languages〉 tell about alternatives, typically, linked to the local clans. The ethnic premise brings to several peoples or races, each one with own genetic patterns. The idiom basis suggests several tutoring and training lines, each one with grammar and syntax specialisation, to assure the fluent control of the particular verbal/written message passing. The spoken tongue is indorsed national mark, with acknowledged writers and newspapers, promoting current changes. Now, the speech, doubtlessly, is essential relational means: dialogs and dialects sustain the clans and form the parental education of the typical familiar unions.

The spoken/written languages are aggregation method of individuals understanding each over, in view to create solid collection setups. The accumulation proceeds, if the relational ways widen, providing tools for structural assets and administrative tasks. Basic references include:

1. The informal relationships, exchanging friendly messages and education records;

2. The agreed protocols, binding the individuals through undersigned conventions;

3. The compulsory bonds, tying the country's citizens, by regular public law rubrics.

The course follows structural conditions, under self-rule organised accretion and self-sufficiency administrative ingenuity. Arrangements and coercions assure the county's legality, once the 〈laws〉 follow recognised «civic modes». The civilisation builds on meme fruition 
drivers, according to the rationality of aware citizens, by completion of interactive mimicry essays, which up to now prove to grant profits. Indeed, the current position of citizens to look at their future faces the dilemma:

1. The a posteriori examination of results, to select plans on statistical forecasts;

2. The a priori faith in the detected «natural laws», to decide on the plan choice.

The impasse is evenly leading to contingency forecasts and plans, built on the «knowledge), i.e., on the current «mind s setups of clans and nations, or, in alternative, it is heading to total projects and schedules, based on the acknowledged existing 〈cosmos' information〉. The alternate path is, mostly, implicit, when the faith in outright 〈laws〉 is especially priced. The men's progress is truly awkward occurrence, to make convincing the existence of absolute 〈back reasons〉. The conjecture avoids provisional frames and looks at outright 〈laws〉, ruling the «natural surrounds〉 as well as the 〈human frames». The leeway to switch from contingent to total worth for the latter ones modifies the relational context, allocating general purpose and appliance to the human laws〉 as well as it is the case with the «natural laws〉, whether believed pertaining to the «cosmos' information».

The 〈collective settings〉 on the earth happen assembling according to the mentioned relational connections, say: communication or market or head ship, namely:

1. The volunteer contacts, based on friendship agreements and free covenants;

2. The contractual links, involving private law obligations and promised leaflets;

3. The imperative bonds, entailing supremacy, by public law to rule the nations.

The communication-to-knowledge track is civilisation basis, with culture/ethics by-products; the market-to-finance one combines agreed protocols, possibly, at conditional sorts; the headship-to-governance one shall establish compulsory ties, enjoying total scopes, at least formally. At the last ranges, the leadership layouts, with the resort to a priori faith, use transcendent either immanent readings; with the recourse to a posteriori analysis, refer to «closed societies», ruled from below by democratic options. When discussing the intellect> formation, the last track keeps on ambiguous routines: the collective settings have tricky organisations, with maybe top down, maybe bottom up architectures. The haziness dissolves, if spoken/written languages are aggregation method. The gathering proceeds and the relational ways widen, by tools for structural assets and administrative tasks, ending the lawfulness architecture by official (sovereignty). The basic ways cover:

1. The agreed protocols, binding the individuals through undersigned conventions;

2. The compulsory bonds, tying the country's citizens by official mandatory rubrics.

The 〈cognition〉 processes permit organising (collective layouts): governing and administrative assemblies keep reference protocols; formal authority establishes lawful arrangements at the civic extension. The humankind has discovered the self-reliance of rural setups, urban programmes and national outfits, because the social relations have invented 〈legality〉, 〈liability〉 and 〈bureaucracy〉 by the ethics, which advises about the community management. The lawfulness inspires to further truths, as if the «cognition〉 does not stops at shared inferences, but it transforms in total value.

\section{The authority formation}

The earth in negligible planet in the universe, without effects elsewhere and future fallouts. It is hard belief that the cosmos' information somehow links with the rational causality of events in the human minds. The conclusion is that all what is happening on our planet is effect of (natural laws) and these, if coherent and cogent, are meaningful, i.e., they imply something. The sentence entails the 〈rational causality〉 hypothesis, surely, haphazard, but justifying what we see and buoying our explanations. At this point, the men are actual singularity or anomaly, out of the universe's course, or they fall in the common cosmos' information. The civilisation deployments are parts of the play; the 〈rational causality〉 appears; we have somebody who becomes aware of it. Many fallouts turn implied and we comfortably face the lucidity of the universe, the daily and seasonal strings or the coherence of gravity effects. At this point, the links between men and world are complex and open to many marvels. We start looking from men-centred locations and move from there.

In the present images, the human running options aim at restricting into provisional and reliant issues, with a posteriori assessments, or, perhaps, at devising reliable upshots, with a priori bents. The latter approach brings to trust in «natural laws〉 as if the cosmos' information carries the total soundness, showing a pre-existing order. The universe's laws are worthwhile, as they converts in 〈knowledge〉, once the human cognizance process starts. The output brings multipart cuts:

1. The steadfast forecast of our backdrop's changes, on daily/ yearly projections;

2. The keen planning/enacting of administration/governance/ supremacy edicts.

The faith in detected 〈natural laws〉 depends on us. What we discern uses light: it spots matter, ignoring antimatter; our physics disregards non-discovered details. On the contrary, if it makes us believe existing a priori inner causes or upper motives, the trust in the devised schemes increases and affects the 〈human laws〉. The human running towards <civilisation〉 is composite occurrence, operating on the surrounds and organising anthropocentric solutions. The multiple outputs apply on turning wilderness, towards culture and ethics by-products; say:

1. The material transformations, handling science and engineering consequences;

2. The intellectual appointments, dealing with lawfulness and morality aftermaths.

The technologies are innovations, modifying the natural order, to enhance effectiveness and to grant steady upgrading. The civic behaviours combine validity, obligation and officialdom, altering the natural order, as well, to organise the societies in villages, towns and nations, with leaders and governments. The pubic constituents, from patriarchal forms to multi-ethnic or trans-gender clans, are essential for the established communities, even if the private components, again, cover similar interpersonal topics. The history of the human civilisation is narration of peoples and kingdoms, of social breakthroughs and wars, of managements and leaderships, etc. because officialdom helps if providing whole worth, to provisional achievements. The 〈progress ) frames fuse in the 〈authority> settings and the history refers sequences of events, suggesting (inner〉 or 〈upper〉 control. 
The selection of kings and the design of reigns follow whole courses, widening the options, to create countries, empires, selfgoverning districts or self-sufficient territories. The idea of «natural〉 or 〈human〉 〈laws〉 with total soundness supplies separate substance, which has to match in mind's worlds: the «sovereignty is notion linked to a priori inner or upper origins, independent on men's will, thus widening the assembly options. The concept of authority, thus, enjoys alternative views:

1. The a priori «inner〉 or 〈upper〉 statutes, connected to the <empire) civic organisation;

2. The a posteriori 〈relational〉 construal, clearly, linked to «nationstate> arrangements.

The first belongs to a separate reality, proved by 〈inner〉 or 〈upper〉 causes; the second reaches its self-reliance, combining loyalty and lawfulness; the civic organisations include three layers, as the initial hints about the human societies' formation have, already, suggested:

1. The understanding and establishment of friendly and responsive dealings;

2. The bilateral connections, shielding the personal freedom and belongings;

3. The top-down rules, forcing uniformity of citizens in front of governments.

The legality is necessary requirement, but the a priori form is explicit with the total view. Via a posteriori way, we entail the «social breakthroughs» of organised folks: at the government range, these involve «closed societies〉, i.e., typically, «nation-states〉; the construction repeats for every community. The change allocates contingent authority to rule for managing and administration functions, i.e., it awards the 〈sovereignty> on the 〈closed society) and on the territory. This road establishes (authority) on 〈democracy), using ballots and referendums and justifying the «legality by <constitution laws〉, enacted to show the 〈will of the people〉. The idiom/trade/govern is the relational route, by which the (closed societies〉 a posteriori affirm their self-sufficiency. The two pictures are, here, discussed, as alternative explanations of the human saga.

\section{The civilisation setting}

The earth is negligible planet in the universe; the human kind plays inconsequential roles by the relational route, tracked through 〈biology〉 and 〈cognition〉 processes. The questionable result aims at joining insignificant local frames and dubious contingent drives. The previous hints suggest that <inner> or 〈upper» reasons could apply, linking the human <civilisation to total truths. The guess is plausible trust, with allotted meaningfulness within the cosmos' information. The cue applies to the concept of 〈sovereignty). Old-style reading refers to «the king by grace of god», to manage total qualities without proving them. Recently, the Darwinism-style looks at 〈gene evolution〉, by natural supremacy (see the lion, savannah's monarch). The resort to back «natural laws〉 is, also, cutting-edge. The recourse to cosmos' information with (inner formulae) enjoys big interest, as if the inborn logic of the universe is safe premise for the mind rationality. The «natural laws〉 help showing our surrounds, via cosmology or atomic physics; in parallel, apt rules apply to the civic accounts, covering the political current happenings, via sovereign «nation-state〉.

The former does not need being justified, because it is outcome of faith in foundation causes. The latter assumes that «closed societies〉, if self-sufficient, are autonomous and self-governing. The motivation is, typically, by-passed, by traditions: God's grace or inhabitants' exclusive idiom. Thus, until today, the ssplit-sovereignty> situation does not ask defence, having recourse to a priori (upper or inner) grounds. The approach creates the SN, Geneva or the UN, New York; it sanctions the independence of any territory, if voted by the inner people, with no consent or control of the other peoples; and so on. The nation identifies by the spoken idiom or dialect, or cultural/ethical habit, or religious tradition. Thereafter, the independence specialises the portion, with benefits, not shared by other countries, at least in the extant frames. Then, the ssplit-sovereignty〉 is option, in which the self-government does not enjoy completeness, but it aims at provisional rehearsals.

The independence of parallel «closed societies〉 is occurrence of primordial ages, when isolated tribes organise on separate territories. With the agricultural revolution, inhabitants and lands link on the tilling cycles: this starts the geography, the country's parcelling; the building of homes and hamlets; the allocation of estates and domains. The human history is reference: the private law is enough, to run the interpersonal duties; the (closed society) affixes the governance complement of the 〈sovereignty). The «nation-state〉 converts model, with symbolising element in the language. The age characterises by the leadership of European countries, collecting the same-idiom groups and converging towards industrial manufacturing technologies. The two issues link together, giving high adeptness without a priori bent, but by productivity and homogeneity, since:

1. The industrial revolution boost throughput by artificial energy and work organisation;

2. The union of peoples by spoken idiom increases the blending and collaboration spirit.

In the human 〈civilisation〉, 〈sovereignty〉 supplies autonomy: the relational formation includes idiom, trade and administration, but only king and reign enjoy supreme authority, with power selfsufficiency of headship. Today, the normality requires being citizen of a «nation-state〉 or else to be refugees. Asylum-seeking migrants exist, chiefly, outlawed, deported or displaced. Citizens need to recognise the sovereignty of their reign and to ignore the parallel reigns. The civic spheres manage interaction practices, from bureaucracy to kingship, supplying rules and habits. The breakup of the countries assumes settled self-reliant territories, by autonomous decisionkeeping freedom. Now, self-sufficiency, actually, dissolves face to the ecology requirements, due to global dependence on the entropic decay of the world's peoples. The citizen' and nations' autonomy is illusion, perhaps, tolerable at early ages, when our earth had scattered inhabitants, loosely spoiling energy; it is no more sustainable, today, when we are sharing the global village, in which spoil and pollution are out of control. The <ecology requests are multiple onuses: apt technical plans define compulsory recycle/recovery figures; government bylaws impose correct behaviour to the global village.

The human «civilisation〉 is, on the earth, promoted by given peoples, which organise their time together by formal «civic orders〉 or synthetic «technical tips». The progress tracks these twin paths, with, now and then, 〈social breakthroughs〉 or «technology revolutions〉 brought by intellect ideas. In the picture, the analyses are men centred: the civilisation is planned modification of the current trends, with recourse to civic organisations and to productivity techniques. Notionally, these paths are contingent, being derived from intellectual schemes; in the further discussions, the exceptional attainments of the human 〈civilisation〉 look after a priori <inner〉 or 〈upper〉 causes, supplying total worth to them. The faith in the primordial cosmos' 
information is option, as said, playing such role. It assumes that the 〈human civilisation〉 is such an outstanding achievement: we shall further look at a priori inner〉 or 〈upper〉 reasons, justifying the occurrence.

\section{The indorsed progression}

The total worth of the human «civilisation〉 attainments inspires to the a priori faith in 〈cogency) and (authority〉. The guess, which accepts building (natural laws> by empirical tests, is basic way of running trends, managing autonomy and competition. The analyses resort to cosmos' information; no direct exchange provides data or hints about the all, but 〈biology〉 and 〈cognition〉 peculiarities are already encoded paradigms. The progression is «natural» feature, covering:

1. The operation ability, starting agentive routes, by gene evolution, to creatures;

2. The cognitive talent, doing cogent constructs, by meme fruition, to knowledge.

The former tells that the 〈biology brings to life beings and life cycles; the individuals single out by two mechanisms: growth and evolution. The latter says that the 〈knowledge〉 is man-built mind assembly, based on two inventions: abstraction and mimicry. The growth assigns the birth-death cycle, with initial development and final decay. The evolution states the gradual adaptation of the lifeforms to the surrounds. The abstraction asserts that the men's brains convert in minds: these create and process the thoughts. The mimicry affirms the 〈relational〉 skill, assigning meanings to brain's views on interpersonal span, so to make emulation and simulation feasible. The imitation is message-passing system, if the community encodes and standardises the chosen imagery by voice words or graphic signs. Indeed, animals perceive and value views, noises and feelings, but just men extract mental concepts, with interpersonal senses, shared by the group, due to learned codes and communicated through the invented and shared languages.

The progression 〈gene evolution/meme fruition〉 shows the creation of structured societies, in which the completion avails of the cogency of rational assistance. The sevolution is selective way permitting to adapt the lifeforms, to their surrounds. The variations occur by involved fitness tests, follow cross settings and avail of collated routing. The 〈fruition〉 fulfils simulation/emulation acts and keeps aware image of outcomes at the interface. The coherence suggests addressing helpful choices, with the profit extended at all the involved people. Thereafter:

1. The agentive enactment, promoting competition survival by gene selfishness;

2. The rational cooperation, aimed at poised social teamwork by meme altruism.

The former level develops along gene evolution patterns, showing the forceful goals of the life classes, with cross-control managed through greediness and self-centredness; humanity is the only species without automatic predatory balancing. The latter level allows meme completion, adding the interpersonal mimicry by-products of the social coordination and collective shared construal. The combined 〈gene/meme) deviations move from encoded data and extend over imitation spells at the intellect range. The genome is example cosmos' information, made readily available on the earth, within the 〈biology〉 course. The mimicry is example humankind competence, established by the relational proficiency, which helps devising the 〈cognition〉 chapter. The «civilisation), if these a priori schemes are in use, identifies all authority, governing and administrative jobs in the <empire) setting. The analyses, in such situations, are, also, said following indorsed progression, as the steps include inner or upper motivations already belonging to the cosmos' order.

The driven conclusions, now, depict the human intellectual results by the relational skills; then, the social organisation deals with «civic orders), roughly, characterised by three options:

1. Agreed plans: the bargain involves each «closed society», with reliant decisions

2. Inner causes: fixed «natural laws〉 exist and men shall follow the given restraints;

3. Upper motives: 〈absolute truths〉 endure and men need to adopt the guidelines.

The first is the contingent range of the «nation-state), with a posteriori connective traits. Both the following turn to a priori traits, enjoying the immanent reasons of the ensuing facts, either the transcendent steering from godlike forces. The three pictures have conformist readings, since the 〈biology〉 and 〈cognition〉 can remain at depending status; the overall worth creates autonomy or independence, so the inner causes or the upper motives happen with self-sufficient management, at total (immanent or transcendent) consistency of the faced (natural laws), when dealing with the sempire) ranges. In particular, the contingent ranges develop as self-rule and self-reliance and fully characterise the «civic orders ? of the existing autonomous social organisations: no extra limitations exist out of the democratic will of the citizens, to be allotted as community's power.

\section{Autonomy and competition}

The depiction by <empires〉, with inner/upper total causes, or by 〈nation-states〉, with draught backing, shows that the public setups of countries and governments are reliable relational options, supplying distinct (authority) infrastructures. The frames identify in the sovereignty, the particular worth that the makeup officialdom supplies: the homeless' independence cannot explore co-work and mimicry bureaucracy, transforming mental riggings, in spendable wealth. Men, in fact, collect in families, clans, tribes and the likes, with leaders and shared rules; the assembly's independence is understood fact and the cogent aggregation roughly distinguishes:

1. If a natural penchant exists, making permanent effects and yielding total bias;

2. If a provisional options form, building exacting drifts, with contingent upshots.

The empire's authority, governing and administrative order supplies gene-built inner cause or god-grace upper reason to hierarchic power; the nation-state's control contributes by democratic commands, on factual layouts. The independence or self-government of the <empire is upfront. Its proof does not need theology; it limits to ask priori foundation, opposing order to chaos and demanding the prodigious recognition of the emperor's selection. The independence compares to addiction or craving, saying that the emperor and the tied lineage are free from the surrounds and can freely programme the jobs to perform. The nation-state has similarly full authority, even if its (autonomy has to face competition challenge against to parallel other nation-states. The self-rule is, now, a posteriori built and not inner or upper inborn trait. The formation, notably, involves the «closed society〉 assembly, since the sovereignty, in democracy, is 
collective upshot. The «nation-state is not single enactment: it might repeat in different organisations; the cogent cooperation is contingent choice, readily modified. The 〈human laws〉, once enacted, exist; each country accepts tax-paying citizens and ban nationless immigrants. Today, the problem of migrants or evacuees or exiles arises, opposed to inhabitants enjoying residence; citizenship is not natural or divine right; it is managed by each nation. The independences defines as marks of self-sufficiency and authority: the democracy tells that assembled citizen allot these marks, ratified by international treaties.

Inner causes or upper motives are beliefs, more than deterministic or heavenly proclivities. The <empire〉 alters the currently passed 〈human〉 laws, to share «natural〉 rate: the independence or selfgovernment of the institution follows: the acknowledged qualities generalise, transforming in (intellectual) official «sovereignty». The «nation-state〉 enjoys social organisation accepting steady «natural laws>, including pace wise 〈authority), 〈govern〉 and 〈administration>; the image tells that the institutes are men's design and different deeds are possible. The parallel independent courses show that antagonism can supply qualified objectives and competition profits from autonomy, by:

1. The <empire officialdom, linked to fit a priori inner or upper foundation reasons;

2. The «nation-state〉 organisation, connected to a posteriori relational construction.

The former does not need being justified, enjoying implicit faith. The latter tells that the «closed societies〉, if self-sufficiency, are autonomous and self-governing. The inhabitants' exclusive idiom is implied fact; it sanctions acknowledging the independence of the territory, if voted by natives, with no consent or control of the other peoples; and so on. The nation identifies by the spoken language or dialect, or cultural/ethical habit, or religious tradition: the independence focuses the portion, with benefits, not shared by other countries. 〈Split-sovereignty〉 is contingent issue: the self-government does not enjoy total foundation, but keeps provisional rehearsals. In the practice, the sovereignty of (empire) and «nation-state) are equivalent, since (competition) and 〈autonomy) allow managing the alleged independence of both institutes. The uniformity of ssplitsovereignty> awards total control, with administrative and executive rules, allotted by international treaties.

The expected total autonomy is odd pick, thinking that the 〈civilisation〉 forms on the 〈progress) since the «cognitive) deployments are intellectual readings, without tangible upkeep. The 〈reign〉 is symbol of power, as if the hierarchic management of tasks and dispositions inscribes in the public organisations of countries with, basically, immaterial trappings; the relational trimmings classify at three ranges, from relative, via professional, to indorsed spheres, namely:

1. The intimate range: the familiar/friendly intercourses allow exchanging outlooks;

2. The private range: the interpersonal dealings supervise the craft and trade tasks;

3. The public range: the governing institutes accomplish the official civic processes.

The creation of more or less complex interaction or business or government transactions enable series of qualified human operations, which improve the worth of the current engagements.
In the conclusion, the sprogress combines tangible and intangible procedures, which ensue adding extra value: the «civilisation〉 happens removing wilderness and allocating abstract qualifications by the recourse to the mind interpersonal inventions. The competition establishes between autonomous assemblies, which, whether enjoying the three range relational accoutrements, can plan separate policies towards expansion. The description equivalently applies to (empire> and to «nation-state), since the (split-sovereignty) is constraint simply required as factual implementation of treaties.

\section{The ecology reversal}

The identification of (progress〉 with the relational trimmings' three ranges is inexact appraisal, as if the human civilisation> builds worth by intangible contents, rather than by transformations of the material reality. The intellectual transactions are men's bias, to identify; the reality gathers particles and fields, with matter/antimatter and energy exchanges. The «cosmos' informations is software complement of the listed hardware: the two are subdued to 〈entropy), the decay of the <order in the material layouts and in the information drafts. The 〈cosmos' order is credible fact, if we acknowledge the human intellect), when the rational processing of ideas enjoys its relational formation. The 〈cosmos' information is meaningless proposition, without a rational <intellect〉, to manage it; the «cosmos' order> supplies helpful hints, only if the coherence runs causal chains.

The 〈entropy〉 tells us that the «cosmos' order deals with irreversibility: the upcoming shall only change towards increased decay, when material transformations occur. The «cosmos' information) entails (entropy) as unavoidable control: gene evolution is manifest constraint of 〈biology〉; meme fruition brings parallel 〈cognition〉 procedures, as mind's construal and as knowledge's application. Only intellect interpersonal processing does not alter the 〈entropy); the applications have material contents and the induced decay inevitably ensues. The 〈cosmos' information〉 covers the «ecology〉 setback; it is clear that material transformations yield downgrading, with, however, free choices:

1. Basic headways, if progression follows mixed tracks, with biological options;

2. Critical decay paths, when depletion and contamination are intensive picks;

3. Conservative tracks, once special top choices address intellectdriven votes.

The elections are possible on earth, because there living beings developed, having agentive and rational abilities, which allow selecting actions and planning goals. The choices traditionally link to devised technologies, which enable suited subsets of makeovers, according to:

a. The «agrarian> revolution, carrying ordered farming, breeding and husbandry;

b. The 〈industry revolution, based on 〈work organisation〉 and energy planning;

c. The intellect) revolution, on-line including artificial life/ intelligence processes.

The «agrarian〉 choices allow exploiting the agentive character of the 〈biology processes, with inroads heading towards natural reproduction and propagation; the <industry> ranges turn to the human sagacity management, also, supported by energy aids; the 〈intellect> 
spans add resorting to artificial life/intelligence, synthetically redoing gene evolution and meme fruition. The wealth creation is just default accomplishment: the (cosmos' information〉 is, maybe, implicit backing; the linked entropy> is total taming fact, little affecting the subsets of human makeovers. Then, (green engineering) is operative anti-pollution remedial; 〈industrial business〉 is efficiency tip; (artificial life/intelligence) is working equivalent. The sprogress> cannot exist with no limits and its planning is conceivable lasting over windows, fixed by facts out of our control. The 〈entropy shows that our wellbeing depends on conditioning constraints, which come before our programming of yearned developments and our management of detected resources.

The dependence of the sprogress> on cosmos' conditioning constraints exists for «empires〉 and for «nation-states». The former situations are implicit, due to their total worth. The latter may use contingency, to manage sorts of self-reliance of parallel cclosed societies> with bottom up ruling, when, in primordial ages, lonely tribes establish on distinct parcels. With the agrarian revolution, inhabitants and lands link on the tilling cycles: this starts the ownership, the land's parcelling, the building of factories and villages, the distribution of estates and domains and so on, ending with the parting in selfsufficient assets and self-ruling politics. The «nation-state becomes reference standard, with language as symbolic paradigm. The deployments express the European countries headship+, converging to industrial layouts and collecting same-idiom clans; the solution fosters efficiency by order and yield, by simplified communication and effectiveness because:

a. the language uniformity enhance the collaboration effectiveness by homogeneity;

b. the integrated design-and-manufacture enjoys work schedules and energy supply.

The 〈nation-state〉 autonomy is self-reliance utopia, as if 〈progress is the automatic outcome of (intellect), namely, as if intangible mental creations provide worth and the value cycles are enough to grant global compensation of effluence snags, for total recovery. In reality, the eecology s shocks ensuing the industrial revolution are severe unbalance, if productivity obliges resorting to artificial energy. The agrarian revolution is the most conservative, since biology entails natural energy only. The intellect revolution does not affect matter or energy, until in thoughts' areas; the entropy asks balancing, if artificial life/intelligence devices have actual exploitation by tangible applications. The technology switches, or revolutions, show a new 〈progress age, once discovered how:

a. manipulating and taking profit from the men breeding of floras and faunas;

b. orderly supplying work-teams and selectively provisioning energy sources;

c. technically exploring the duplication of life/intelligence processes as helps.

The agrarian, industrial and intellect ages differ because the involved 〈knowledge〉 specialises in altered ways, i.e.: to up-bring domestic plants and animals, to use work organisation and synthetic matter transformations, or to include artificial life/intelligence gears. The each time widened data allow enabling purposely-devised processes, aimed at useful products and produces, by enhanced productivity and efficiency, via, possibly, controlled pollution and recovery. The farming, fabricate and conceive are human options, showing that the reality can follow modified paths, by proficient governance and controlled operation programmes.

\section{The dependence and the rescue}

The sprogress is human chance, based on the capabilities, at relational skills, having sociability, business and ascendancy schemes of the established assembled groups. The erection of pertinent interpersonal bonds promotes the spot reliance of the people within each group, each time, with the formation of the appropriate social architecture, supplying:

a. the decision and operation autonomy of individuals and clans, for self-government;

b. the civil homogeneity of all the natives, against profit, efficiency and cross-liability;

c. the hierarchic patterns for sovereignty management, maybe, in contingency cases.

The civic building allocates personal self-sufficiency; it aims at plans and duties independence, if organising the shared nation; it hypothesises ranked layouts, when settling the authority, perhaps, at just conditional ranges. The three layers do not remain within relational context; if «technology revolutions〉 apply, the performed processes modify the surrounds, increasing the 〈entropy〉 decay. The personal self-sufficiency does not exist, when performing material changes: the outputs affect everyone and the damage is shared onus of people not profiting by the changes. The autonomy is misleading claim, since the <ecology falloffs add everywhere, with like drawbacks. The 〈progress is composite result, dividing societies or «nation-states〉 at unlike wellbeing levels. The routine lists series of developed or underdeveloped (countries). They distinguish due to welfare apparatuses, with benefits and facilities, helping the inner citizens. The tax scheme is congruently heavy, since the control autonomy structure covers many duties, moved to the public sphere and charged as private levy. The series of duties, tolls and tariffs make the official makeup expensive; in like time, they create several administrative jobs for the inner bureaucracy.

The «nation-states〉 profit by higher efficiency, compared to parallel institutes; they may enjoy century-old layouts, with domestic traditions including idiom and epic independency wars against similar institutions. Strong divisive education develops via the teaching of the partisan history, in conflict by patriotic annals, telling grand rivalry narrations. Recently only, the autonomy is object of discussion, especially, in reason of the comparative profits that competition allows. The debate brings to the set of European rival countries, opposed to itinerant peoples; lately, to the European Union, EU, merging sets of settled nations. The close, for now, demotes single stateless expatriates and prises the «nation-state union, if the merging in bigger countries is out of reach.

The invention of the <empire or of the «nation-state leads to 〈sovereign〉 relational assemblies; these have hierarchical settings, with, today, the governments, elected by democratic rules and fit administration by bureaucracies. In conclusion, the sunion of sovereign states> is current standard way, to formalise the 〈sovereignty〉 relational patterns: for the 〈empire〉, the outlines possess total foundation; for the «nation-state situation, they transform in contingent «split-sovereignty〉. This unifying issue is possible, since the 〈democracy〉 supposes self-clamed 〈sovereign〉 individuals, so that the grouping into 〈closed societies〉 permits ratifying 〈split-sovereign〉 institutes, haying full autonomy, when dealing with the 〈civic modes〉. 
When considering the «ecology constraints», the dependence remains critical and the effects might rise to be serious drawbacks. The result obliges revising the definition of 〈sovereignty), limiting the operation spheres to the «civic modes) and, in any case, keeping the <ecology domains» within the ones out of the men open exploitation.

The 〈sovereignty> limitations, when dealing with the <empire's〉 institute are, perhaps, implicit, since the 〈human laws〉 happen belonging to the «natural laws and, as such, enjoying proper total force. Then, the <ecology constraints s share a priori foundation, fixed the world over, with unified rules; the imperial indorsing has universal cogency with legitimation ratified having over-all worth. When dealing with the «nation-state), the 〈human laws are a posteriori design, having contingent worth, through the relational patterns of self-named 〈sovereign〉 individuals. The 〈ecology kerb) is further control, a priori restraining the earth's inhabitants, wanting (global village uniformity. The 〈split-sovereign〉 does not allocates autonomy to the «nation-states〉, when the lawfulness involves the surrounding protection and restoring measures. The sprogress> is, perhaps, written in the «natural laws〉 as 〈cosmos' information〉; it is, perhaps, built on relational patterns because of the men's skills. The linked concept, anyhow, is provisional, since the 〈entropy) tells us that the decay is general end. The 〈sovereignty> has similar ratification: the related definition, indeed, has contingent value, as the 〈ecology tells us that consumption and contamination are necessary complement of the material transformations, invent and undertaken in the human civilisation. Apparently, 〈entropy〉 and 〈ecology shall belong to the 〈cosmos' order»; 〈progress〉 and 〈sovereignty〉 are, instead, 〈mind's beliefs>, with contingent consistency. Then, the two notions shall modify: (progress> proves the rational cogency to prefer advances; «sovereignty) shows the lucid selection of autonomous decisional schemes. The concepts need to keep suitable consistency, in any case, with the pre-existing (cosmos' information».

\section{Conclusion}

The <ecology) requires modifying some «truths, notably, the ones concerning the relationships with local official authority. The safeguard of the environment affects the 〈global village`, entailing resource depletion and pollution increases. Entropy grows; the balance deals with choosing a mix of intangible sources and of retrieved goods, which defuses spoils at overall ranges. The technical features have somehow settled specs; the management schedules cannot permit local freedom: 〈split-sovereignty〉 and lack of supranational authority combine, to make impossible the needed cogent regulation. The situation is plain, if we derive the power architecture by relational models, from assembled citizens. The a priori upper or inner backing looks at «king by grace of God», either at 〈Darwin's selective supremacy>, mixing human responsibilities and extra biasing beliefs.

The a priori beliefs ensue from faiths in transcendent routing either in merging of meme fruition into gene evolution, with unified deterministic trends. Transcendence is out of empirical evidence; uniformity inhibits glitches, e.g., multi-cultural/ethnic states (Switzerland, etc.), enclave-countries in even cultural/ethnic territory (San Marino Republic, etc.). The a posteriori schemes best suit to create «nation-states» and coherent procedures entrust government and leaders. Next, bottom up path of 〈democracy〉 presumes sovereign citizens, which indorse central assembly's power: so, the authority becomes executive by hierarchical frames. Apparently, alternative settings exist: a. capitalism: the citizens manage the economic power and delegate the political one;

b. communism: the central assembly manages the total political and economic power.

The today actual enactments follow hybrid socialism settings, with tax systems ruled by central authorities, redistributing wealth, to equalise the citizens' means, still keeping private ownership. Similar social organisations build by a priori schemes: private rivalry, notably, refers to Darwin's competition; godlike dominance shows central ruling. These layouts have inner or upper controls, thus they readily include limitations and the <ecology restraints〉 can be readily active, if the appeal arises. The current readings accept unspoken fusion of models and the relational developments are sometimes understood event, dealing with extra constraints, even if their origin is difficult to find out. Anyway, 〈split-sovereignty〉 is layout, in which implied notions are simultaneously sharing top down and bottom up vindications, but the latter need adding explicit external ruling.

Indeed, the a posteriori rationalisations foster on three relational ties: communication, business and authority, having informal, private and public regulation of the links. The dealings' complexity are unknown to all other living beings, starting at the informal level, with the sophisticated verbal and written intercourses, to the creation of formal levels, due to the shared civic modes. The rift of private from public regulation, possibly, means that two formal levels distinguish: (nation-state formation is standard issue, if a relational top layer exists, doing government tasks. The transfer of citizens' sovereignty to central assembly's power is regular topic, to rationalise the public law, with the set of formal edicts, passed by the 〈authority>. Next, the private law runs at front interpersonal level, moving the public law at the indirect one, to rationalise the regular topic, made necessary by the power delegation to the representative central assemblies.

The 〈relational〉 model is useful reference, when the empirical contingent descriptions deal with abstract intellect creations. The a priori upper or inner models enjoy total truth, with transcendent (grace of God kingship) or immanent (Darwin's selective headship) back-up; the models are jointly exclusive, still, the allusion to absolute accounts inspires reading the anthropic facts, which assign one or the other frame to figure out sovereign (empires) and «nation-states〉. With the 〈relational〉 model, we start by classing as 〈sovereign〉, the citizens; then, the related 〈closed society〉 forms the sovereign «nationstate〉, with contingent consistency: parallel countries enjoy «splitsovereignty>, with officially equivalent authority. The process is clearcut: the «sovereignty〉 relocation, from the single, to the assembly, allots executive power, to the enacted law: the ideas of lone intellects are not yet tangible; size and composition of the «closed societies> are arguable points; the a posteriori validations play roles, keeping formal and informal tricks. The building of these interpersonal traits requires weird mimicry and emulation abilities, educating agentive skill by rational flair; by men's centred pictures, the analyses address the single-to-collective trails, towards abstraction:

a. the gene evolution trail to selfish behaviours and competitive aims, for hegemony;

b. the meme fruition trail to altruism manners and cooperative goals, for helpfulness.

The former trail uses agentive skill to interact with the environs, adapting life issues and styles. The 〈relational〉 model moves along the latter, once informal layers start and formal levels happen to follow 
clever managements. The selfishness-to-altruism variation shows appraisals by which the collective processing modifies the current quality of the personal relationships in steady clans. The changes need the invention of abstract concepts and synthetic bonds assigned via agreed clues. If the abstraction works, notionally, the human 〈minds〉 duplicate the reality by mental models, once conformist restitutions allow that the clan enjoys conjoint understanding. The shared 〈knowledge is conventional construal, retaining idioms and dialects to grant comprehension and devising laws and rules to assure administration. The 〈knowledge is intellect by-product defined and exchanged at the interpersonal range, inferred as culture and ethics pieces, once the backing bonds possess right extension and explicit conception. The initial 〈relational> layer establishes «communication〉 between educated 〈minds»: the execution follows meme fruition by creating intellectual images to encode the experimental instant views, according to interpersonal conformist restitution.

The interpersonal encoding brings to spoken/written languages, stated at the tribal range, with imitation of contiguous peoples. On the back, the formulation of abstract concepts allows delaying their utilisation: the ideas are open to personal exploitation, whether effects do not damage third people; the plans are men's option, justifying progress' expectation. The altruism suggests helpful prospects: the indorsement of lawfulness by formal edicts; at individual stage, private regulation is necessary and public ruling shall add, if parallel nation-states operate. The 〈rationality is virtue of interactive «minds», understanding, through simulation of future events, the 〈legality〉 worth. The global village's safety entails a sole empire: it is useless conceiving interstate rules; selfishness or altruism concerns individuals, involving the communism vs. capitalism dilemma or the socialism graduation of the two. Does consciousness or wisdom affect collective or single minds?

The 〈democracy〉 happens transferring 〈control〉 to central united government: 〈nation-states〉 and 〈split-sovereignty〉 replicate rivalry for power, just asking solidarity with socialism ratio, at the country's range. The wisdom of collective minds has to face the lack of individual responsibility: in like measure, between sovereign citizen and sovereign «nation-state), we obtain the indorsing of formal levels, to rule invented relational links by civic official institutes. The meme fruition stages become crucial, with allied authority schemes; the ethics' management entails central bodies, with delegated power and joint tasks and reliability. The collective rationality and wisdom build on the twin levels: merging sets of personal ideas; creating organisations, with centred «control». Then:

a. the logic establishes comparing individual projections by structured mental plans;

b. the intelligence forms choosing shared solutions, via emulation/ simulation design.

The 〈relational〉 model tells that the individual/collective〉 trail has twin force: the 〈knowledge〉, culture and ethics, assembles spontaneous soundness cues, to be used, when organising thoughts and minds; the setting concludes by implementing, after instinctive, formal 〈relational〉 layers, to shape the civic organisation. A synthetic reading suggests preliminary cues. Three relational layers typify the extant 〈split-sovereignty> layouts, with parallel «nation-states〉. The communication links leave selfishness, to mate-citizens' solidarity, starting formal layers with the business and authority ones. The public regulation begins by (nation-state〉 solidarity and most likely, shall end by (global village〉 altruism. The formal ruling becomes possible at relational stages, when the collective trails have severe codes with cogent requests; the outcome has equivalence in endorsed establishments and the authority enjoys compulsory strength, according to 〈lawfulness principles. The relational layers are middle tools to shape the intellect creations, between clans or nations: the mind worlds are meaningful, if structured doctrines become common credos: maybe, the procedure fulfilment needs formal indorsement and compulsory responsibility. This explains the further authority layer, after the direct communication and business ones.

The analyses turn around the earth's oddities 〈biology> and «cognition», which justify identifying responsible individuals and creating explaining knowledge. The «relational» layouts allow showing (in the nature) three relational layers: communication, business and authority, promoting multiple social makeups, with civic (friendly, private or public) connectivity. The quoted earth's oddities are the human peculiarities showing how the knowledge has automatic projections in the shaping of the 〈civilisation : the topics are object of (below quoted) books, debating the «cognitives strategies from natural and artificial 〈life〉 and (intellect〉 viewpoints. Once natural 〈biology〉 and (cognition) enjoy plausible guesses, the artificial duplications follow. Then, face to the <ecology requests, the relational models and the a priori beliefs so well link, to see in their complementary issues useful explanation cues. The 〈relational〉 model limits at providing tools, describing how communication, business and authority layers may establish, when individual/collective〉 trails are mental mimicry 〈logic〉 and intelligence〉 implements. The outcomes are contingent; still the complementarity with the a priori beliefs opens hints towards alternative total views, enjoying special appreciation. The all, surely, requires attention. ${ }^{1,2}$

\section{Acknowledgments}

None.

\section{Conflicts of interest}

Author declares that there is no conflict of interest.

\section{References}

1. RC Michelini di San Martino. Robot-age knowledge changeover. New York: Nova Sci; 2009.

2. RC Michelini di San Martino. Cognitive revolution quest: human civilisation prospects. Roma: Aracne Ed; 2016. 